\title{
Concept formation and art: Basic experiment and controls'
}

\author{
RICHARD D. WALK \\ THE GEORGE WASHINGTON UNIVERSITY
}

The experiment tested adult Ss'ability to learn the concept of an artist's style. On the pretest Ss were shown colored slides of a painting and guessed the artist. During training new slides paired paintings with the names of artists. On the posttest the original pretest slides and new ones were shown. Ss demonstrated concept learning by improving on the posttest as compared to the pretest. A control group where names were not paired with pictures during training showed no improvement.

In the classic type of concept formation the $\mathrm{E}$ chooses a concept, usually a fairly simple one, which is known to him and unknown to the S. The task of the $S$ is to "discover" the correct concept, and, once it is known, the concept usually is easy to apply. Much of concept learning is exemplified here. For other concepts, however, the positive instances themselves define the concept. We can extend this type of concept into new or hitherto unknown examples on the basis of our experience with these positive instances, but the underlying $E^{\prime} s$ definition of the concept may be a matter of disagreement, even among experts.

An artist's or a composer's style represents such a concept. The conceptual style can be defined with reference to positive instances, and then the extension of it into new instances can be studied. But, since the criteria that define the concept are hard to identify, perhaps in some cases even illusory, we do not expect that the $S$ will learn from the positive instances to be perfectly accurate in applying the "concept" to new instances. This type of concept formation is somewhat analogous to the probabilistic cue experiments reported by Bruner, Goodnow, \& Austin (1956), except that the probabilistic cues are difficult to define. Courses in art appreciation have used the underlying method of the present experiment for many years.

The method was to show selections of artists' work to the $\mathrm{S}$. He was asked to guess the artist of each selection. This constituted the baseline. Then a training series was given, followed by a posttest to determine if the training had improved the person's ability to recognize work of the artists shown in the pretest.

The artists chosen for study were Cézanne, Degas, Manet, Matisse, Monet, and Renoir. These artists are not necessarily the best that might be chosen as representative of, roughly, the impressionistic school, nor are the paintings selected the best for the experiment. Rather, they represented the artists for whom six Kodachrome colored slides of their paintings were available at this time. Such slides could rarely be found in art books, and so some very "unrepresentative" pictures of an artist's conceptual style were obtained.

The general method was to give slides on the pretest and the same slides in the posttest to determine if the training was effective. Additional slides, not used in the pretest, were a control, as described by Solomon (1949), to find out whether the training extended beyond the slides used at the beginning. The Ss were given the names of the artists prior to the pretest and told to guess on each trial. This was to insure chance accuracy (17\%), at least, and to make certain that posttest scores would not be inflated simply because Ss then knew the names of the artists. One group of Ss (familiarization only) was given the entire series with no pairing of correct artists with paintings during the training series. This group was a control to find out if the training may have simply reactivated prior memory.

Method

A total of 36 different Kodachrome slides (six for each artist) was used. All artists' signatures were covered by tape. Six slides were presented during the pretest, where the $S$ tried to identify the artist but received no knowledge of results. Then, four different training series were conducted. In each training series Ss guessed the artist on a slide, and this was followed by a slide with the artist's name and the title of the painting on it. Each series was presented three times in a different order. After the four training series the posttest was given, where 12 slides were chosen, two from each artist, and six of these slides had not been used on the pretest. Slides on the pretest were mixed so that the individual pretest pictures were not the same for all Ss, but the 12 posttest slides were identical for all. No information as to correctness of judgment was given on the posttest. The general method was similar to that of Hull (1920) in concept formation except for the noinformation pretest and posttest.

A random procedure was used to select slides for each series, except that very familiar paintings (such as a Renoir nude and a Degas ballet scene) were placed in the training series.

This experiment was conducted in groups. The Sscollege students in an introductory psychology coursewrote answers in booklets, and the names of the artists were written on the blackboard to help the Ss remember them. Fifty-one Ss from three sections 
Table 1

\begin{tabular}{|c|c|c|}
\hline \multicolumn{3}{|c|}{ Accuracy of identification of artists in the pretest and the posttest } \\
\hline Artist & Pretest & Posttest \\
\hline \multirow[t]{2}{*}{$\overline{\text { Cézanne }}$} & $20 \%$ & $34 \%$ \\
\hline & & $36 \%$ \\
\hline \multirow[t]{2}{*}{ Degas } & $24 \%$ & $46 \%$ \\
\hline & & $44 \%$ \\
\hline \multirow[t]{2}{*}{ Manet } & $20 \%$ & $44 \%$ \\
\hline & & $38 \%$ \\
\hline \multirow[t]{2}{*}{ Matisse } & $24 \%$ & $32 \%$ \\
\hline & & $46 \%$ \\
\hline \multirow[t]{2}{*}{ Monet } & $22 \%$ & $46 \%$ \\
\hline & & $50 \%$ \\
\hline \multirow[t]{4}{*}{ Renoir } & $28 \%$ & $56 \%$ \\
\hline & & $56 \%$ \\
\hline & Average & $43 \%$ \\
\hline & & $45 \%$ \\
\hline
\end{tabular}

were in the regular experimental group. One section of students $(\mathrm{N}=16)$ received the entire experiment (all pretesting, training, and posttesting) with no identification.

Results

(1) Definite concept learning occurred (see Table 1). Whereas $23 \%$ of the slides were correctly identified on the pretest, the identification of the same six slides on the posttest rose to $43 \%$.

(2) The slides not used on the pretest were identified with $45 \%$ accuracy on the posttest.

(3) The familiarization control group had $16 \%$ correct identification on the pretest and $22 \%$ on the posttest, a slight, but not significant, rise in accuracy. ${ }^{2}$

\section{Discussion}

This experiment has demonstrated "concept" learning of an artist's style. What are some of its implications?
The traditional concept learning experiment has the advantage that the $\mathrm{E}$ has chosen fairly specific stimulus dimensions. An artist's style may be more hard to define in words and difficult to communicate. While less specific, an artist's style does approach some kinds of "daily life" concepts in being a sum total of many difficult to describe experiences, a probabilistic weighted cue type of concept learning. Through the study of the complexities of an artist's style one can obtain insights into how this type of concept is learned and perhaps find dimensions that have implications for simpler, more controlled studies.

Students differ in the extent to which they can utilize information presented in the training series to make higher scores on the posttest. Improvement scores may be related to "perceptual" or "Intuitive" thinking, to "creativity" or to other intellectual processes.

The basic experiment can be varied in many ways, such as methods of stimulus presentation, types of prior experience, or the use of different artists, to understand this type of conceptual behavior. The experiment can also be used with children to help understand the development of cognitive-perceptual processes.

References

BRUNER, J. S., GOODNOW, J. J., \& AUSTIN, G. A. A study of thinking. New York: Wiley, 1956.

HULL, C. L. Quantitative aspects of the evolution of concepts. Psychol. Monogr., 1920, 28, No. 123.

SOLOMON, R. L. An extension of control group design. Psychol Bull, $1949,46,137-150$.

\section{Notes}

1. The experiment was performed at Cornell University in 1958. Analysis was partially supported by NIH Grant HD-00203.

2. The basic experiment was also carried out with music with different Ss $(\mathrm{N}=43)$ where Beethoven, Brahms, Dvorak, Mozart, Rossini, and Tchaikovsky were the composers chosen. No concept formation was demonstrated: $25 \%$ accuracy in pretest, $24 \%$ correct with the same selections on the posttest, and $26 \%$ accuracy on the six new posttest selections. 